\title{
Boda Bodas In Kenya Have Alleviated Boys From Poverty, Idleness And Bad Habits Despite Prevailing Challenges
}

\author{
Veronica Onjoro Phd ${ }^{1}$, Rebecca Bwari Arogo Phd ${ }^{2}$ Dr.Lucy ${ }^{3}$, \\ Fr.Stephen Osiche Phd ${ }^{4}$ \\ ${ }^{1}$ Student Mount Kenya University P O Box 342 Thika \\ ${ }^{2,3}$ Student Mount Kenya University \\ ${ }^{4}$ Student Catholic University
}

\begin{abstract}
Beginning of the 1960s, Ugandan smugglers needed a cheap, reliable, and quiet way to move materials between Uganda and Kenya. Cars were too expensive and noisy, and so were motorbikes. Their choice was to use bicycles which, with a little luggage rack behind the seat, were perfect for evading the border police while transporting valuable goods. The idea had an unexpected development. Those bikes were so strong that perhaps were also suitable as taxis to transport people. Michael Lipton, identified rural isolation and distance from urban centers as the real obstacle to the growth of developing countries (Lipton 2014). The gains were lower than those derived from smuggling, but at least the business was legal and the riders did not have to deal with the police system of the two countries. This development gave rise to the Boda Boda taxi system which, from the border between Uganda and Kenya, where it was invented spread quickly in east Africa. The widespread development of motorcycle taxis system in Kenya is changing the mobility habits of the rural populations. Their ubiquitous presence in East African cities is the result of a number of factors including an increasing demand for public transit, the ability to purchase motorcycles on credit, and an influx of cheap imports from Indian manufacturers like Bajaj. In the countries where they are present, boda boda can provide vital job opportunities for entrepreneurial young men who lack skills lifting their incomes and brightening their lives while at the same time resulting in an increase in road accidents and unnecessary deaths. The term boda boda may come from the English words shouted by their drivers: "border, border". Some credit the boda boda with an apocryphal ability to transport people across a border without a need to complete the paperwork using a motor vehicle would necessitate. The need for a reliable and effective transportation system is increasingly met by an organization of young men called Boda Boda. The name still carries its outlaw's origins and it is a mispronunciation of the words "border border," which just reminds the smuggling practices of the 1960s. Today it has become a common means of transportation especially in rural areas of Africa. The motorcycle Boda Boda, more robust and with a better ability to go longer distances and climb up hill compared to the bicycle, first appeared on the market in 1992, and had a rapid growth due to the Government easing on the restrictions on import of vehicles more than 5 years old (Howe 2003). The cheapness of the imported used motorcycles, compared to the cost of cars caused the fleet growth, and the success of the phenomenon. The utilization of a transportation system which freely permits the access to a larger amount of ideas might become an element which will allow populations to decide what their future should look like.
\end{abstract}

\section{Introduction}

Boda Boda service is perceived as a tool primarily to fulfill the needs for participation in the social life of the wider community and that being part of this community requires visits and contact with people outside of one's home village. boda boda transport sub-sector is growing at a very high rate and creating jobs for thousands of youths in the region and as such the government cannot ignore them. So many youths are earning their daily bread in this sub-sector and some county are be fully involved make sure that they thrives even more, Following the end of British rule in East Africa, the amount of paperwork required for motor vehicles crossing through the area between the borders of the newly independent nations of Kenya and Uganda dramatically increased. Passing through this area, also known as "no-man's-land," required a cumbersome stack of paperwork to be filled out (once before entering this ill-defined area, and once again promptly after leaving it). Eventually, out of this bureaucracy, a business idea was born: people soon began offering bicycle rides across no-man's-land, allowing passengers to avoid the paperwork that was necessary for motor vehicles. It began in the southern border town of Busia, where there is over half a mile between the border posts, and it soon spread to the northern border town of Malaba. Vying for the attention of potential customers looking for a quick ride through, bicycle drivers would shout out "boda-boda!" (Meaning "border-to-border"). Of course, in Kampala, there are no borders being crossed, and the bicycles have been replaced by loud, polluting motorcycles. Nevertheless, the name "boda-boda" remains. It is interesting to remark how the utilization of the service is scarce in terms of access to the western elements of welfare. The access to education is limited to the schools 
locally provided by the Government. It must be acknowledged that the primary schools, which are located close to many villages, even though are easily reachable on foot have scarce quality. The data shows that quality education is not the primary concern for remote rural families. This fact is that average family disregards the importance of education; the reality which has to be dealt with by development agencies is that in the poorest areas other priorities assume importance. A child has to be close to the village because he/she needs to work in the family garden, taking care of the herds, thus providing financial support to the family. Every day they travel around $50 \mathrm{Km}$, and this factor, together with accidents and the dust they inhale, leads to illnesses and weakness is not difficult to become a Boda Boda motorcycle operator. The only requirement is to buy or rent a bike.

\section{Presentation}

Boda boda operate where more conventional services are uneconomic or physically impossible. They are found in urban and rural areas where they act primarily as feeder services to the towns or major public transport routes. Role played by the boda boda industry is the alleviation of the livelihoods of young people. Sometimes they flout the law and carry up to four passengers instead of one. Because of their limited capacity travel costs per km are 2-7 times those of large capacity buses, but cheaper than sole hire taxis. Their popularity derives from the convenience they offer and ability to meet demands that other services cannot. Whilst the poorest make only occasional use of boda boda, due to low income and high cost constraints, for many they provide identifiable ways of enhancing income by extending the range and intensity of productive activities. the youth break rules with impunity.Sometimes the arrest of one of them for a traffic offence is met with raucous demonstrations. Their greatest impact on the poor is through the employment provided. Operators are drawn mostly from the least educated classes and each is shown to support an average of 6 dependants including themselves. Boda boda primarily provide three types of - predominantly - short-distance services: within the main urban areas, where they compete with conventional sole hire taxis and taxis; as feeders to urban areas on routes that due either to the low density of demand or the roughness of the route - are unattractive to taxis; and as feeders to the main roads in which role they tend to complement taxi and large capacity bus services.

\section{Statement Of The Problem}

Lack of jobs is one of the problems in a country like Kenya which is progressing. In the rural and urban areas the youth have embraced boda boda as godsend as it has provided them jobs and now they can earn money as young as they are. The lack of connection between remote and urban populations reduces the opportunities given to rural communities, to have access to basic services or to influence the institutions and policies that could improve the quality of life of the community. Most young men after they finish primary schools and secondary schools start looking for friends in town and villages to pass of time. With their idleness such boys start having ideas of stealing drug taking and mischieve.But with the onset of boda bodas, aait have made the boys busy bringing food to the table in their homes reducing insecurity in the villages and towns. Development must be understood even in remote areas, as a process of increasing people's opportunities to self-determination, which has to be experienced in the private and socio/political sphere. Moreover, the social exclusion, in these remote areas in terms of non-participation in the country's political and economic processes also implies an irreparable loss of human capital, which might jeopardize future growth. Boda boda riders sometimes are hired by gangsters who rob shops and residences and by politicians to cause chaos in meetings. The boda boda riders are notorious law breakers, flouting road rules and getting involved in crime. Sometimes the boda boda riders can cause upto six accidents per week.

\section{Methodology}

The study was based on a target population of about 350.The study was based in kitale, bungoma, kisumu,kisii and Eldoret counties. The study involved boda boda riders, residents, hospital attendants, and data from NTSC. The technique used was Simple random sampling. In a simple random sample (SRS) of a given size, all such subsets of the frame are given an equal probability. Furthermore, any given pair of elements has the same chance of selection as any other such pair (and similarly for triples, and so on). This minimizes bias and simplifies analysis of results. In particular, the variance between individual results within the sample is a good indicator of variance in the overall population, which makes it relatively easy to estimate the accuracy of results. The target population of this study was 350 of which $30 \%$ of sample size was drawn from. This will give us 100 respondents. The data was collected through questionnaires, newspapers interviews, journals, phone and desktop.

\section{Advantage}

Speed: Nairobi is notorious for its traffic jams, known locally simply as "jams." A boda rider, however, enjoys certain immunity to traffic. The boda simply zips around, weaving around cars and potholes as idle automobile drivers enviously watch it speed by. If there is a "jam" and you need to be somewhere by a 
certain time, a boda really is your only option. Price: Bodas are very cost-efficient. A ride across town goes for about 500 in a taxi (approximate 50 dollars). In a hired car, that same ride would cost about four or five times as much.

Street excitement: It must be said: sitting on the back of a boda can and will make the rider feel like a badass. With the wind in his face, he nonchalantly gazes into the horizon ahead. Locals stare in awe, impressed with the foreigner's bravery and ability to master this new culture with ease. In congested conditions the motorcycles are also valued for their ability to weave through the traffic and shorten door-to-door journey times. Middle-income users tell you they use boda boda when 'in a hurry'. In isolated areas they may be the only alternative to walking. It has been suggested that in this respect their absence from some villages may be due to the lack of repair facilities and the capital and technical knowledge to set them up. Boda boda also have a not insignificant goods carrying function in the industrial parts of the main cities, and at harvest time in rural areas. One estimate is that this function comprises $30 \%$ of urban and rural operations. Provide jobs to thousand of youths; they are cheap, easy to find. . Many youths in Kenya are unemployed and that's why most of them have sought for other ways of improving their living standards like venturing into 'boda boda' industry as a business. It's quite encouraging that these sectors have employed quite a large number of youths regardless of their education level. Among other benefits of this sector are as follows: Employment- it has reduced the number of idle minds through direct and indirect employment thus reducing the danger of gangs and drug abuse among the youth. Income generation- it is a source of income to most people and thus improves the living standard of an individual. Accessibility- motorcycle is flexible and one can access to places where motor vehicles cannot access. Saves time- it is only meant for one person and hence one does not need to wait for a long time to be ridden to the destination. Generally, it is one industry that has boosted the country's economy in terms of revenue. The Boda Boda motorcycle taxi system has become a fairly reliable, rapid and relatively cheap service which can pass on dirt roads that are too difficult for car and go longer distances and into steeper terrain that would be possible with a bicycle. Functionally, Boda Boda are used for kids and teachers to go to school, workers and employees to go to work and, in the villages, it facilitates travel to markets and health facilities. The motorcycle taxi driver, however, is not an easy job and it is currently only for the young men. In a distance of 100 meters there must be a homestead where they own a bodaboda motorcycle.

\section{Disadvantage}

In Kenya boda boda are the leading causes of accidents because the boys need a training of two days to be riders, they do not adhere to traffic rules, they want to make much money, they sometimes drink alcohol or take drugs while relaxing, they do not sleep early, some sleep late. A lot of money coming to their possession makes them want to enjoy life to the fullest. Some are cannot be trusted to carry children to school but they end up raping them. Some marry girls in upper classes and in secondary schools. Studies have shown that most pregnancies are caused tby boda boda riders. A further indication that the Boda Boda job is dangerous comes from the local press which, citing police reports, states that between 2008 and 2012 the injuries among drivers increased from 2000 to 3043 (NTSC). The number of accidents increased since then as more, untrained riders, took advantage of the tax exemption to earn from the industry. Some of the reasons attributed to these accidents are overloading by carrying more than two passengers, riding under the influence of drugs and alcohol and not using precautionary measures such as helmet .Motorcycles, or "Boda Bodas," are characterized by high speed and maneuverability, hence one can travel many kilometers at a constant speed depending on the desire of the customer. Since the 1960s they have eased transportation needs across the country, which can be attributed to their ability to penetrate to remotely located areas. In the recent past, however, motorcycles have been linked to insecurity across Kenyan towns and villages as terrorists, bandits and robbers use them to accomplish their immoral missions. "(Boda Boda) are only beneficial to malicious fellows who are out to kill and steal. Some boda bodas are hired to kill or snatch handbags from people. Kidnappers have taken advantage of such bikes to fulfil their maliciously oriented desires across the country. Terrorists have extended their immoral activities across the country, more especially in the north eastern part of the country, where the use of bikes as a mode of transportation is preferred due to its speed and accessibility. Not only are the "Boda Boda" riders perpetrators of crimes, but they are also prone to attacks themselves. "Boda Bodas have proved to be the shortest route to death. Many Boda Boda operators have suffered on the rough hands of killers, who kill them after stealing from them the money they have worked hard for, they equally confiscate [from] them the motorbikes. Many boda boda riders are losing their lives to thieves who not only steal the motorcycles they also kill them. This is happening all over Kenya. The size of the money sums involved acts as a magnet to the politicians and criminal world. It seems likely, therefore, that the boda boda associations will become like the taxi counterparts and lose their orientation in favour of the welfare of members. Ownership of the associations is also likely to become more contested and to defeat the ambition of a truly national organisation offering a wider range of services, such as credit and cheaper vehicles through direct imports. Boda boda business has grown tremendously and its contribution towards poverty reduction cannot be gainsaid. 


\section{Conclusion}

Let all boda boda riders be registered in their counties and each be given a registration number and the hours of operations be spelt out in each county. Let them also be registered in Sacco's to help them in case of injuries and deaths. National Government through the Ministry for Transport and Infrastructure should come up with a code of ethics for boda boda riders in the country. The code of ethics will maintain public trust and credibility of the boda boda business which he termed as a profession. It is clear that the boda boda industry has made a significant and unique contribution to the conduct of economic and social activities in Uganda by providing services in circumstances where the main alternative is to walk, which is slow, expensive as a means of load carriage, and of limited capacity. The low-capacity of boda boda enables them to service demands that other forms of transport would find uneconomic, albeit at a relatively high unit travel cost. They provide service coverage in previously inaccessible rural and urban areas, and also enhance the profitability and effectiveness of more conventional transport services by feeding and distributing passengers to and from major stops. Information is still lacking on which areas have services, which do not, and the reasons for the differences. It has been suggested that their absence from some isolated areas may be due to the lack of repair facilities and the capital and technical knowledge to set them up. So far as the poor are concerned the major benefit to date has been employment in the industry. This has mainly benefited poorly educated male breadwinners who have few other employment opportunities. They in turn support the livelihoods of an estimated 1.6 million people. Low incomes and high unit fare costs means that the poorest are only occasional users of the services per se. However, if these infrequent trips overcome critical access constraints (e.g. to health or education facilities) they may have high associated social benefits. Greater use of boda boda by the poor requires an increase in their income, or a reduction in fares through greater competition and lower vehicle operating costs. Let security personnel do checks at night of those operating at night to get rid of killers. The first measure is not really a transport sector issue. Elimination of unnecessary government taxes on entry to the industry, and the establishment of credit finance schemes to widen ownership and increase competition, seem the best way to achieve a short-term lowering of operating costs and fares. There is also a case for investigating the need for a national boda boda maintenance-training programme, combined with small enterprise loan support, to enable services to start in villages where they are currently absent. A switch to newer vehicles, in the case of motorcycles, and better maintenance through education of operators and training of mechanics, are longer-term but more difficult ways of lowering costs. The increasing market share of Chinese-manufactured motorcycles will lower the age of the fleet and reduce costs, but government action will be required to raise maintenance standards. Let original spare parts be separated from the fake ones which could be contributing to a lot of accidents in Kenya. The main benefits associated with boda boda services are their poor safety record and the pollution created in urban areas by concentrations of motorcycles. Some county government facilitates the formation of saccos in the county to enable the riders get soft loans for development. Operator education and training, to be provided by the associations, offer the main ways of addressing these issues, backed by an appropriate programme of enforcement. Specific measures may need to be identified from international experience to address the issue of motorcycle exhaust pollution, as this is likely to become critical in the near future. Boda boda riders operate under the NTSA Regulations 2015 for motorcycles, which came into force on January 12016 and which seek to tame boda boda accidents and attract a fine not exceeding Sh20, 000 or a jail term of not more than six months or both for offenders.

\section{References}

[1] Amimo, P. (2001): Busia's wheels of survival. Daily Nation, Wednesday January 17, 2001.

[2] Howe, J. and S. Iyiola Oni (1996): Nigeria downsizes to motorbikes. Sustainable Transport, Number 6, Summer 1996. www.itdp.org

[3] Lipton, M. (1977). Why poor people stay poor: A study of urban bias in world development. Cambridge: Harvard University Press.

[4] Ministry of Works, Housing and Communications (2001): Road management and financing study. Executive Summary Volume 1. Final Report, March, (BKS (Pty) Ltd).

[5] Pankaj, T. (1991): Designing low-cost rural transport components to reach the poor. Infrastructure Notes Transport No. RD-2. March, Washington, DC (The World Bank).

[6] Warr, P. (2005). Road Development and Poverty Reduction: The Case of Lao PDR 